\title{
SUSTAINABILITY MULTIVARIATE ANALYSIS BASED ON THE GLOBAL REPORTING INITIATIVE (GRI) FRAMEWORK, USING AS A CASE STUDY: BRAZIL COMPARED TO SPAIN AND PORTUGAL
}

\author{
N. TEJEDOR-FLORES, P. GALINDO-VILLARDÓN \& P. VICENTE-GALINDO \\ Department of Statistics, University of Salamanca, Salamanca, Spain.
}

\begin{abstract}
The main objective of this research is to find the sustainability gradients of Brazilian companies and sort them as a function of economic, environmental and social components, using multivariate methods for dichotomous data, in order to establish the foundations for better knowledge of the trends and sustainability reporting habits of Brazil. The methodology used is a combined approach, comprising Principal Coordinates Analysis (PCoA) and Logistic Regression Model (LRM) to build an External Logistics Biplot (ELB). We found that the most sustainable companies are associated with great concern for biodiversity, conservation and air pollution prevention, as well as with the strong relationship with employees, human rights promotion and fighting against child labour and forced labour. We conclude that it is possible to obtain sustainability gradients not only for Brazil but also for any country that uses the GRI framework, applying the ELB.

Keywords: Brazil, corporate social responsibility, external logistics biplot, global reporting initiative, sustainable development.
\end{abstract}

\section{INTRODUCTION}

Until the late 80s, the environment and its relationship with the economic growth and social justice was not a priority subject in international and national agendas. This situation started changing with the emergence of the sustainable development concept that consolidated in 1987 with the publication of the paper 'Our common future' also known as the Brundtland report.

In this report, sustainable development is defined as 'development, which meets the needs of current generations without compromising the ability of future generations to meet their own needs' [1]. By extending the concept, we could also talk about a sustainable society as one that over generations does not consume its resources nor produce more pollutants than those nature is capable of degrading [2]. Under this concept, nowadays, it would be difficult to think of societies where companies are just entities exclusively oriented to the generation of profits for their shareholders. Corporate Social Responsibility (CSR) has gradually become relevant along with the creation of economic value. This paper describes a new methodology capable of accessing in detail how companies are contributing to a country's sustainability.

\section{THE GLOBAL REPORTING INITIATIVE (GRI) REPORTS}

The demand for information and transparency from companies has increased over the last few years. Public awareness and interest in social, environmental and ethical issues and 
increased attention from the mass media have resulted in more companies making social disclosures about themselves [3-5].

To satisfy these expectations and inform about sustainability in a clear and open way, the GRI was founded in 1997. Its roots lie in the US non-profit organizations the Coalition for Environmentally Responsible Economies (CERES) and the Tellus Institute.

GRI is an international independent organization that helps businesses, governments and other organizations understand and communicate the impact of business on critical sustainability issues such as climate change, human rights, corruption and many others [6].

This paper addresses the G3.1 and G3 Guideline reports corresponding to the third generation of the GRI. They envision a sustainable global economy which combines long-term profitability with social justice and environmental care. The G3.1 and G3 Guidelines are organized into three categories: Economic, Environment and Social. The Social category is extended into the following subcategories: labour, human rights, society and product responsibility. The G3.1 Guidelines are an update and completion of G3, with expanded guidance on reporting gender, community and human rights.

\section{A CASE STUDY: BRAZIL}

It is gradually becoming clearer that the publication of social and environmental information depends on each country [7]. International comparison studies such as Adams et al. [8], Azzone et al. [9] and Fekrat et al. [10] indicate variations between countries. However, very few studies focus on developing countries $[11,12]$; the most cited studies are strongly dominated by USA research and a minority of work from elsewhere [7].

This study uses Brazil as a case of study since most of the current studies are based on Anglo-Saxon countries, but it is still necessary to develop similar studies with different geographic, cultural and institutional contexts. Moreover, Brazil became aware of the necessity of incrementing the social commitment of companies several decades ago. Therefore, the main objective of this study is to analyse the economic, environmental and social sustainability tendencies of Brazilian companies and to determine if the corporate features that characterise these corporate strategies have a European influence, as shown in Perez-Batres, Miller and Pisani [13] and Rangan and Drummond [14].

Spain and Portugal are compared to Brazil mainly because of the economic relationship between Brazil and Spain [15-17] and also because CSR determinants in Continental Europe remain relatively unknown, especially in Portugal [18].

\section{METHOD}

\subsection{Database of Brazilian companies}

In order to create the database, all Brazilian companies of all sizes (small, medium and large) and all sectors, which made reports according to GRI criteria from 2011 to 2013, were chosen. The data collection was done through the database available at the GRI website (http:// database.globalreporting.org/search).

A total of 377 sustainability reports updated to May 5, 2015 were downloaded, as shown in Table 1. Subsequent updates were not taken into account for this research.

The data used in this paper were organised in an IxJ binary data matrix in which the I rows correspond to the companies and the $\mathrm{J}$ columns correspond to 55 binary characters (or indices) corresponding to six dimensions: Economic Dimension (Economic performance EC1, 
Table 1: Database of Brazilian companies.

\begin{tabular}{lrrc}
\hline \multicolumn{4}{c}{ Sustainability reports } \\
$\mathrm{N}=377$ \\
\hline Year & 2011 & 2012 & 2013 \\
$\mathrm{n}$ & 145 & 139 & 93 \\
\hline
\end{tabular}

EC2, EC3, EC4), (Market presence EC6, EC7), (Indirect economic impacts EC8); Environmental Dimension (Materials EC6, EC7), (Energy EN3, EN4), (Water EN8), (Biodiversity EN11, EN12), (Emissions, effluents and waste EN16, EN17, EN19, EN20, EN21, EN22, EN23), (Products and services EN26, EN27), (Compliance EN28); Labour Practices and Decent Work Dimension (Employment LA1, LA2, LA15), (Labour/management relations LA4, LA5), (Occupational health and safety LA7, LA8), (Training and education LA10), (Diversity and equal opportunity LA13), (Equal remuneration for woman and men LA14); Human Rights Dimension (Investment and procurement practices HR1, HR2, HR3), (Nondiscrimination HR4), (Freedom of association and collective bargaining HR5), (Child labour HR6), (Forced and compulsory labour HR7), (Assessment HR10), (Remediation HR11); Society Dimension (Local Communities SO1, SO9, SO10), (Corruption SO2, SO3, SO4), (Public policy SO5), (Compliance SO8); and Product Responsibility Dimension (Customer health and safety PR1), (Product and service labelling PR3), (Marketing communications PR6), (Compliance PR9). All binary variables take the value of 1 when the characteristic is present and 0 in its absence.

\subsection{Statistical methods}

During the bibliographical survey, it was found that Principal Component Analysis (PCA) and the Factor Analysis (FA) have been widely used to conduct similar studies. However these methods are inadequate for binary data [19]. To understand the sustainability gradients (or latent composite indices) of the companies and their relationship to the observed characteristics and their graphical representation, an algorithm, as proposed by Vicente-Villardon, Galindo-Villardon \& Blazquez-Zaballos was applied [20]. This algorithm is later extended by an integrated approach as suggested by Demey et al. [21]. This combinatory method comprises a Principal Coordinates Analysis (PCoA) and Logistic Regression Model (LRM) to construct an External Logistic Biplot (ELB).

The technique presents the companies as points and the sustainability indices as vectors on a scattergram as a means of exploring the main characteristics of the database. Some additional information about the goodness of fit of each index is also provided. This method has been used by Vicente-Galindo et al. [19], to analyse the behavioural patterns of innovation for different regions.

\subsubsection{External logistic biplot application}

The algorithm starts with a PCoA to order the companies in the Euclidean space based on the latent gradients. The next step of the algorithm consists of adjusting an LRM for each variable by using the latent gradients as independent variables. The quality of representation of each variable is measured as a combination of three indices: the p-value of the logistic 
regression, in order to test the relation of the solution and each variable (using deviance); the Nagelkerke-R squared; and the percentage of correct classifications, using 0.5 as a cut-off point for the expected probability.

In specific analytical terms the plot is interpreted according to the following rules:

- Distances between company points on the scattergram are inversely related to their profile similarities, i.e. companies close together have similar characteristics.

- The angles between vectors representing the variables and factorial axis, estimate the degree of the relation between the variable and the latent dimension. Taking into account that the horizontal axis is the one which always accounts for most information, variables forming acute angles with the first axis are the most relevant to ordering the companies in relation to the more important gradient of sustainability; that is to classify companies according to sustainability.

- The projections of the companies onto the vector representing the variables, estimate the expected probability of the characteristic for that company given its combination of characteristics.

- The length of the vector that represents each variable indicates the discriminating power of the variable in separating the companies. Shorter vectors are those with the greatest discriminatory power (as long as their information is adequately represented on the plot).

The Logistic Biplots were calculated using MULTBIPLOT [22], based on the Matlab code available in http://biplot.usal.es/ClassicalBiplot/index.html.

\section{ANALYSIS OF RESULTS}

\subsection{Exploratory analysis}

Large companies are the ones that represent over $80 \%$ of companies over the 3 years, being the most interested in applying the sustainability indicators within their policies, which coincides with most of the studies that found a relationship between the size of the company and the scope of the social responsibility publications. Besides, the media and the general public demand more information from large companies than from small ones [5, 23-26].

A total of 55 main indicators corresponding to the 6 dimensions in the years 2011, 2012 and 2013 were analysed. In the Economic Dimension the most reported indicator in the 3 years was the Economic performance indicator EC1, related with the generated and distributed economical value, which includes: incomes, costs, donations and other investments in the communities; in Brazil: $90 \%$ of the companies reported this indicator in 2011, while $89 \%$ of them did so in 2012 and 2013. Since this information is usually displayed in the financial statements of all companies, the performance indicator was expected to be the most reported economic indicator [6].

In the Environmental Dimension, EN8 related to total water drawing and EN22 related to waste generation, were the most reported indicators. In 2011, $78 \%$ of companies reported both. In 2012, 83\% and 80\% reported EN8 and EN22, respectively. And in 2013, 74\% and $82 \%$ of the companies reported the indicator EN8 and EN22, respectively.

In the Social Dimension, LA1 from labour practices and humane working conditions indicator was the most reported indicator by all the companies during the 3 years. This indicator is related to the workers broken down by type of job, contract, region and sex. Over $90 \%$ of 
the companies did report this indicator. In the Human Rights area, HR6, related to child labour and measures to eradicate it, was the most reported indicator. In the Society area, SO1, related to the local community programs, was the most reported indicator. In the Responsibility on the Product area, PR9 related to regulatory compliance was the most reported indicator, Fig. 1.

\subsection{Logistic biplot with external information}

\subsubsection{Gradients of sustainability}

As a means of obtaining the main gradients of sustainability and their relation to the observed characteristics and graphical representation, we apply the ELB algorithm.

The first principal plane (2D solutions) accounts for $37.43 \%$ of variability. The first eigenvalue of 26.97 is significantly higher than the second eigenvalue, meaning that even if the two sustainability gradients are considered, the first (horizontal) dimension accounts for most of the information, as shown in Table 2. The overall goodness of fit (average of the goodness of
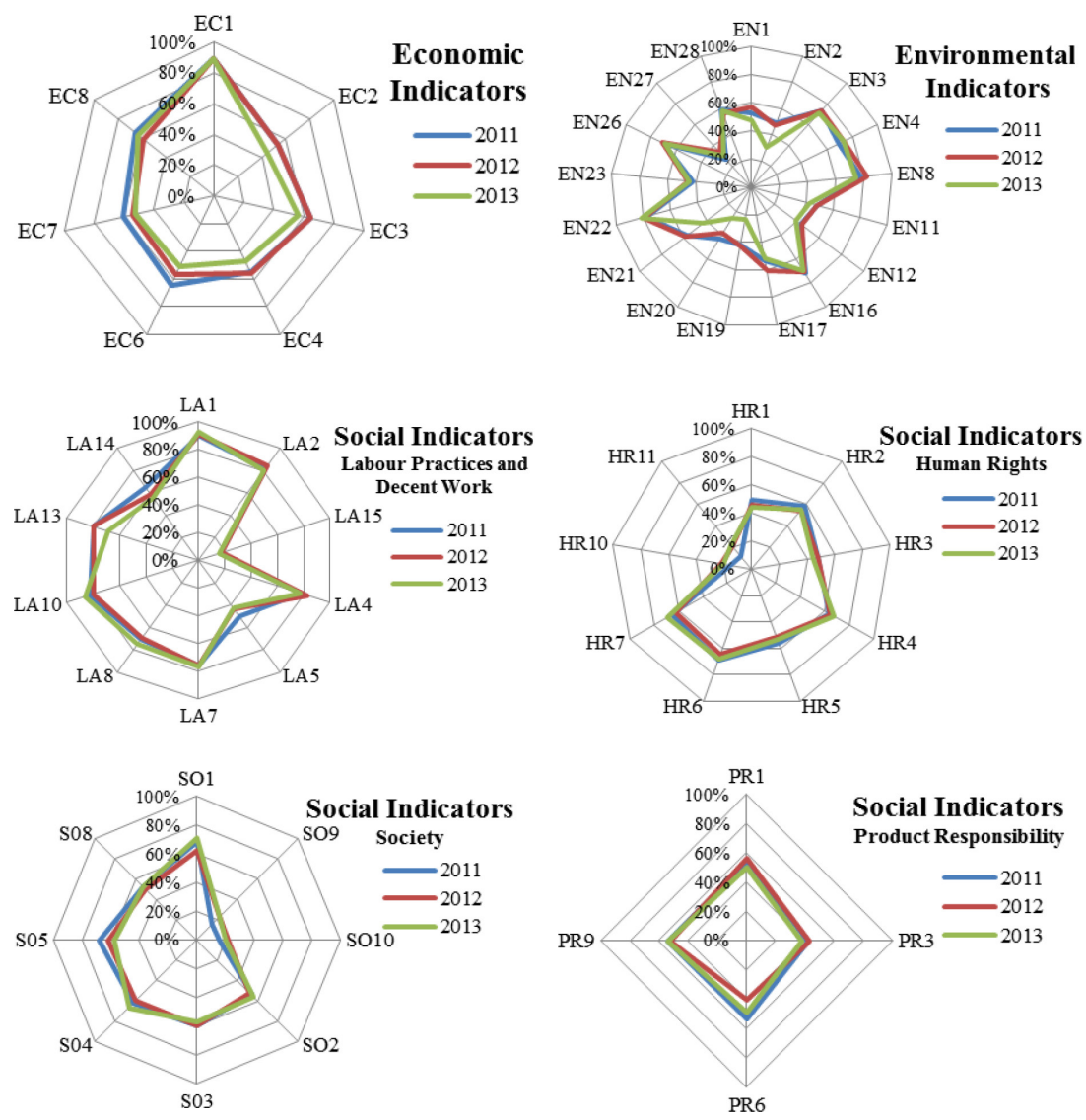

Figure 1: Spider graphs. Reporting (\%) for core indicators conforming economic, environmental and social dimensions of sustainability in Brazil. 
Table 2: Logistic biplot with external information.

Retained axes and explained variance

\begin{tabular}{lccc}
\hline Axes & Eigenvalue & \% of variance & Cumulative $\%$ \\
\hline 1 & 26.9721 & 33.3796 & 33.3796 \\
2 & 3.2754 & 4.0535 & 37.4332 \\
\hline
\end{tabular}

fit for each variable) as a percentage of correct classification in the biplot is $81.25 \%$, so the two dimensional solution is sufficient to explore the main features of the data.

As for the sustainability gradient interpretation, the cosines of the angles are useful to interpret how variables are related to each gradient. In summary, we have found two main gradients. The first one is related to EN11, EN12, EN20, LA5, LA8, HR3, HR5, HR6 and HR7. Therefore, the first sustainability gradient could be defined through them. This first gradient is associated with biodiversity, emission of greenhouse gases, the relationship of the company with their workers, human rights, the fighting against child labour and forced labour. The companies located on the right side of factorial axis 1 report more of these indicators related to the first gradient that those located in the left side, Fig. 2.

The second sustainability gradient comprises the variables: LA15, HR10, HR11, SO9 and SO10. This gradient is associated with the social dimension related to employment, human rights evaluation and local communities. The companies located above the factorial axis 1 have greater values for these indicators as opposed to those located in the bottom end, Fig. 2.

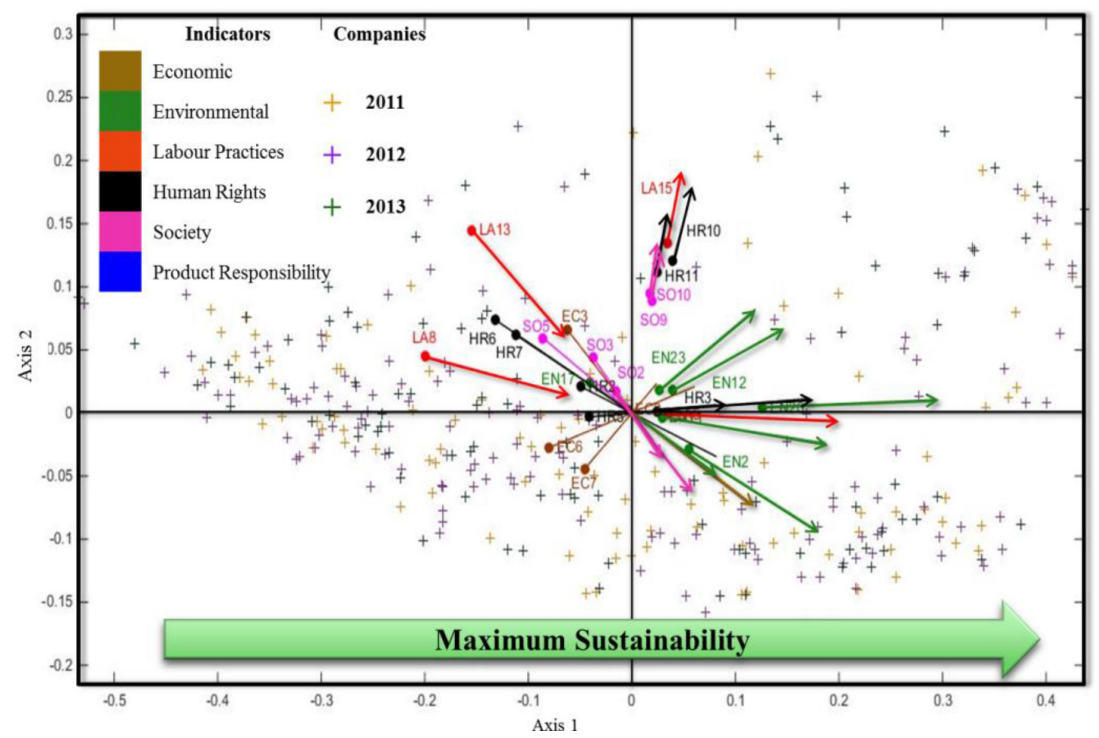

Figure 2: External logistic biplot, based on sustainability data from Brazilian companies. 


\subsubsection{Clusters of sustainability}

To create clusters of companies with a similar profiles of sustainability we use Ward's method of hierarchical clustering with the ordination scores from the Logistic Biplot.

In Brazil, companies located on the right side of Fig. 3 were found to be the group of most sustainable companies (Cluster 3) during 2011, 2012 and 2013. These companies are then associated with a great concern for biodiversity conservation and air pollution prevention as well as a strong relationship with their employees, while maintaining respect for and promotion of human rights and the fighting against child labour and forced labour. Cluster 3 comprises 140 companies (37.14\%) of which $90 \%$ belong to the Water and Energy Sector $(36.43 \%)$. This is the group with the highest report qualifications $(\mathrm{A}+$ and $\mathrm{A})$ and sustainability reports verified by the GRI (i.e. GRI-checked). It has been speculated from a wide range of theoretical perspectives that big companies from environmentally sensitive sectors are expected to voluntarily publish information regarding their social and environmental activities [7]. It is also more likely that bigger companies considered social responsibility activities and their disclosure as a way to improve their corporate reputation [18].

Cluster 2, located in the centre of the 1-2 plane comprises 87 companies $(23.08 \%)$ of which $70(80.46 \%)$ are big companies. These companies mostly belong to the Service and Industrial Sectors at $33.33 \%$ and $32.18 \%$, respectively. These companies do not carry out activities related to the promotion and the evaluation of human rights. They also have little participation with the local communities. Being located in the centre of the 1-2 plane, very few activities are observed in the defined sustainability gradients.

Cluster 1, located on the left side of the $\mathrm{x}$-axis in the 1-2 plane, comprises a group of companies considered as the less sustainable in the present study. This group includes 150 companies $(39.79 \%)$ of which 110 belong to the category of large companies $(73.33 \%)$ mostly from the Services Sector (47.33\%). Construction and Health Services companies are also included in this cluster, Fig. 3.

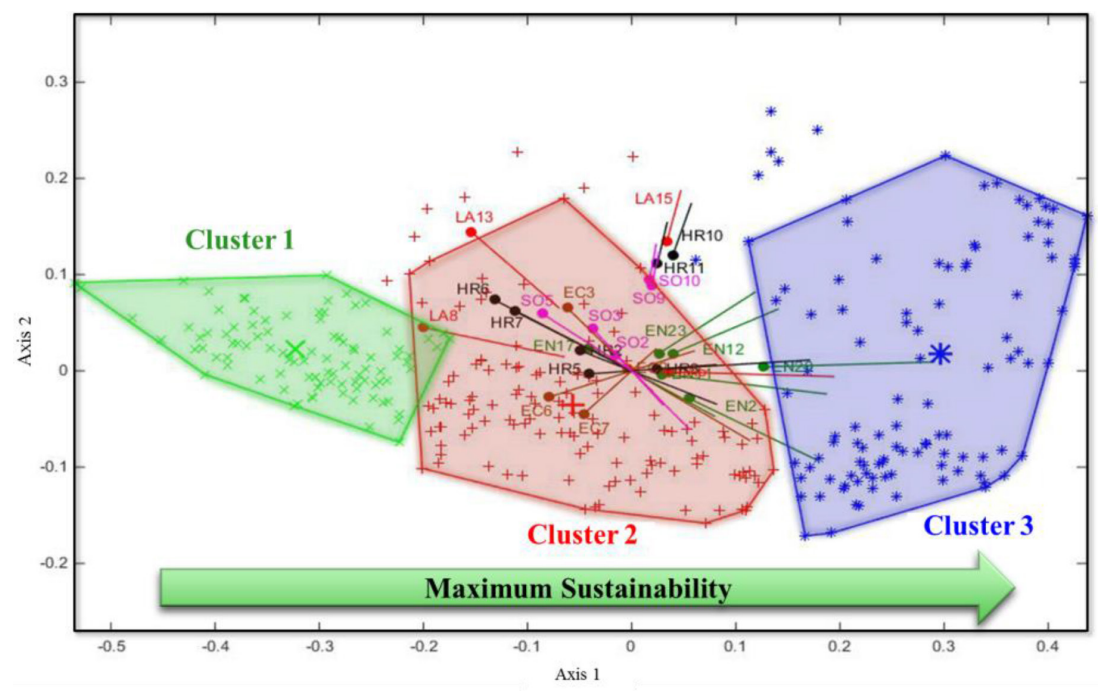

Figure 3: External logistic biplot with clusters. 


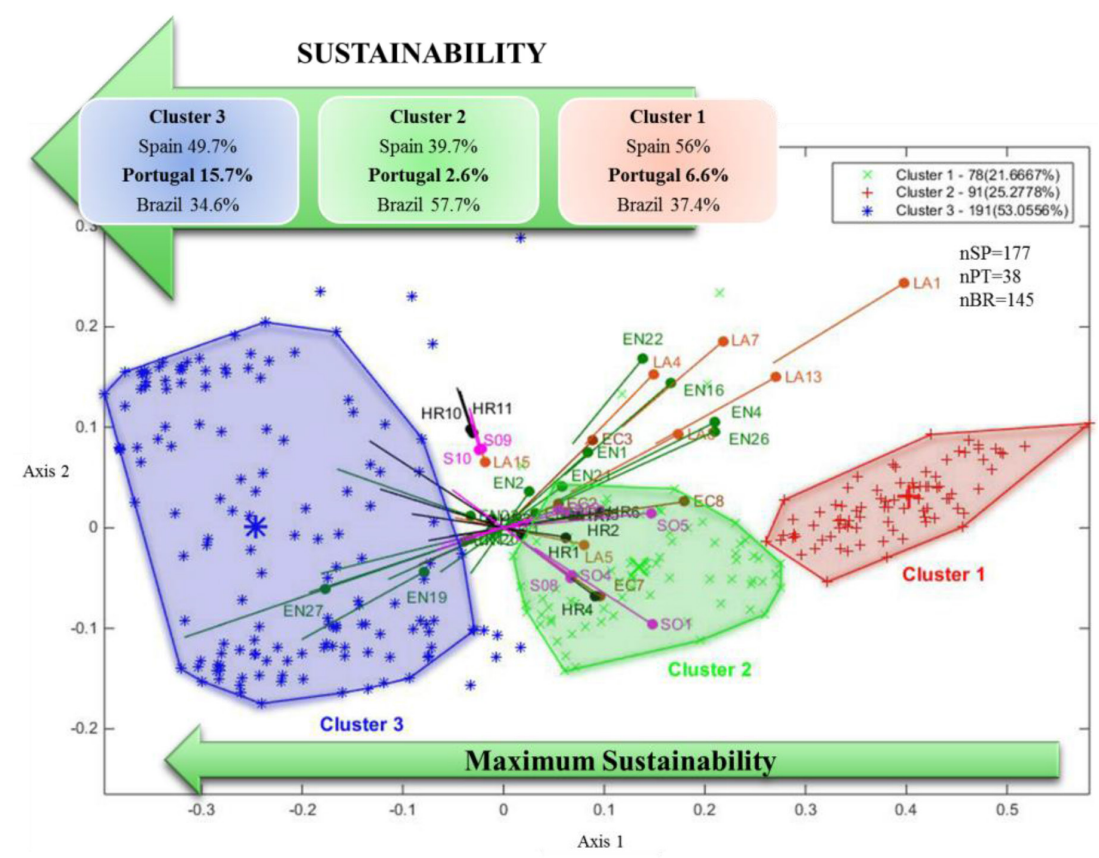

Figure 4: Cluster distribution from minimum to maximum sustainability: Comparing Brazil to Spain and Portugal.

\subsection{Comparison of Brazil with Spain and Portugal}

Gray [27] suggests that the cultural differences between countries could explain the differences in corporate communication patterns.

For this section of the study, a total of 360 companies (including 145 Brazilian companies, 177 Spanish companies and 38 Portuguese companies) were analysed. 78 of these companies were grouped in Cluster 1, 91 in Cluster 2 and 191 in Cluster 3, Fig. 4.

The group of less sustainable companies is found in Cluster 1 located on the right side of the $\mathrm{x}$-axis. This group is made up of 56.04\% Spanish companies, 6.59\% Portuguese companies and $37.36 \%$ Brazilian companies, mostly from the category of small companies (53.85\%). Cluster 2 comprises 91 companies, of which $57.70 \%$ are Brazilian. While it is true that these companies do not include all the indicators, it is important to note that these Brazilian companies have a sustainability tendency and present a higher homogeneity with Spanish companies (39.7\%) than with Portuguese companies. Cluster 3 groups the most sustainable companies with common tendencies regarding the sustainability indicator reports. This group comprises 191 companies: about half of them are Spanish companies (49.74\%) and $15.71 \%$ and $34.55 \%$ are Portuguese and Brazilian companies, respectively.

Based on the results obtained from comparing Spain, Portugal and Brazil, it can be observed that the Spanish companies are the ones with the highest percentage of sustainability records in Cluster 3 that corresponds to the cluster with the greatest sustainability, followed by the Brazilian companies. However, Portugal has more sustainable companies per country compared to Spain and Brazil, despite the low number of published reports. 


\section{CONCLUSIONS}

According to the results obtained in the present study it can be concluded that:

1. A lot of companies view their RSC reports as a way to guarantee the credibility of the published information. To achieve this, they make use of the reliable and credible framework provided by GRI for the preparation of sustainability reports. These reports contain the basic information to understand the sustainability gradients of the companies with the help of multivariate models through economic, environmental and social indicators.

2. The first sustainability gradient in Brazil is associated with biodiversity and greenhouse gas emissions along with the relationship between the company and their employees and the social component related to human rights and the fighting against child labour and forced. The second gradient is related to the social dimension regarding employment evaluations of human rights and local communities.

3. The most sustainable group during 2011, 2012 and 2013 comprises 140 companies of which $90 \%$ belong to the category of large companies, mostly from the Water and Energy sector.

4. Based on the results obtained from comparing Spain, Portugal and Brazil, it can be observed that the Spanish companies have the greatest number of sustainability records publications, followed by the Brazilian companies. However, if the percentage of sustainable companies per country is evaluated, it is clear that Portugal has an advantage over Spain and Brazil despite the low number of published reports.

\section{REFERENCES}

[1] Brundtland, G.H., Report of the world commission on environment and development: our common future (the brundtland report). Medicine, Conflict and Survival, 4(1), p. 16, 1987.

[2] Nebel, B.J. \& Wright, R.T., Ciencias ambientales: ecología y desarrollo sostenible, Prentice Hall: Mexico, p. 14, 1999.

[3] Ho, L. \& Taylor, M., An empirical analysis of triple bottom-line reporting and it's determinants: evidence from the United States and Japan. Journal of International Financial Management \& Accounting, 18(2), pp. 123-150, 2007. http://dx.doi.org/10.1111/j.1467-646X.2007.01010.x

[4] Rouf, A., The corporate social responsibility disclosure: a study of listed companies in Bangladesh. Business and Economics Research Journal, 2(3), pp. 19-32, 2011.

[5] Patten, D., Exposure, legitimacy and social disclosure. Journal of Accounting and Public Policy, 10(4), pp. 297-308, 1991. http://dx.doi.org/10.1016/0278-4254(91)90003-3

[6] Global Reporting Initiative, Guía para la elaboración de Memorias de Sostenibilidad. The Resorce Library Web Site, Amsterdam, Netherlands, available at https://goo.gl/YI1YtD

[7] Gray, R., Javad, M., Power, D. \& Sinclair, C.D., Social and environmental disclosure and corporate characteristics: a research note and extension. Journal of Business Finance and Accounting, 28(3-4), pp. 327-356, 2011.

[8] Adams, C.A., Hill, W.Y. \& Roberts, C.B., Corporate social reporting practices in western europe: legitimating corporate behaviour. British Accounting Review, 30(1), pp. 1-21, 1998. http://dx.doi.org/10.1006/bare.1997.0060

[9] Azzone, G., Manzini, R. \& Noci, G., Evolutionary trends in environmental reporting. Business Strategy and the Environment, 5(4), pp. 219-230, 1996.

http://dx.doi.org/10.1002/(SICI)1099-0836(199612)5:4<219::AID-BSE69>3.0.CO;2-K 
[10] Fekrat, M.A., Inclan, C. \& Petroni, D., Corporate environmental disclosures: competitive disclosure hypothesis using 1991 annual report data. International Journal of Accounting, 31(2), pp. 175-195, 1996.

http://dx.doi.org/10.1016/S0020-7063(96)90003-5

[11] Hossain, M., Islam, K. \& Andrew, J., Corporate social and environmental disclosure in developing countries: evidence from bangladesh. Proceeding of the Asian Pacific Conference on International Accounting Issues, Hawaii, pp. 1-22, 2006.

[12] Porwal, L.S. \& Sharma, N., Social responsibility disclosure by Indian companies. The Chartered Accountant (India), 39(8), pp. 630-634, 1991.

[13] Perez-Batres, L.A., Miller, V.V. \& Pisani, M.J., CSR, sustainability and the meaning of global reporting for Latin American corporations. Journal of Business Ethics, 91(S2), pp.193-209, 2010. http://dx.doi.org/10.1007/s10551-010-0614-y

[14] Rangan, S. \& Drummond, A., Explaining out - comes in competition among foreign multinationals in a focal host market. Strategic Management Journal, 25(3), pp. 285-293, 2004.

http://dx.doi.org/10.1002/smj.375

[15] Solana, G., Brasil: un gran mercado en expansión sostenida, Universidad Antonio Nebrija-Grupo Santander: España, pp. 199-206, 2012.

[16] Malamud, C., Relaciones España-Brasil, Real Instituto Elcano: España, pp. 19-38, 2014.

[17] De la Dehesa, G., La importancia de Brasil para la economía española (Chapter 4). Brasil: un gran mercado en expansión sostenida, Universidad Antonio Nebrija-Grupo Santander: España, pp. 65-71, 2009.

[18] Branco, M.C. \& Rodrigues, L.L., Factors influencing social responsibility disclosure by portuguese companies. Journal of Business Ethics, 83(4), pp. 685-701, 2008. http://dx.doi.org/10.1007/s10551-007-9658-z

[19] Vicente-Galindo, P., Vaz, E. \& de Noronha, T., How corporations deal with reporting sustainability: assessment using the multicriteria logistic biplot approach. Systems, 3(1), pp. 6-26, 2015. http://dx.doi.org/10.3390/systems3010006

[20] Vicente-Villardon, J.L., Galindo-Villardon, M.P. \& Blazquez-Zaballos, A., Logistic Biplots in Multiple Correspondence Analysis and Related Methods, Statistics in Social and Behavioural Sciences Series: Boca Raton, London and New York, pp. 503-521, 2006. http://dx.doi.org/10.1201/9781420011319.ch23

[21] Demey, J.R., Vicente-Villardon, J.L., Galindo-Villardon, M.P. \& Zambrano, A.Y., Identifying molecular markers associated with classification of genotypes by external logistic biplots. Bioinformatics, 24(24), pp. 2832-2838, 2008. http://dx.doi.org/10.1093/bioinformatics/btn552

[22] MULTBIPLOT, A package for Multivariate Analysis using Biplots [Software]. España: Departamento de Estadística, Universidad de Salamanca, available at http://biplot.usal. es/ClassicalBiplot/index.html, Vicente-Villardón, J.L., 2015.

[23] Trotman, K. \& Bradley, G., Associations between social responsibility, disclosure and characteristics of companies. Accounting, Organizations and Society, 6(4), pp. 355-362, 1981.

http://dx.doi.org/10.1016/0361-3682(81)90014-3 
[24] Cowen, S., Ferreri, L. \& Parker, L., The impact of corporate characteristics on social responsibility disclosure: a typology and frequency-based analysis. Accounting, Organizations and Society, 12(2), pp. 111-122, 1987. http://dx.doi.org/10.1016/0361-3682(87)90001-8

[25] Belkaoui, A. \& Karpik, P., Determinants of the corporate decision to disclose social information. Accounting, Auditing and Accountability Journal, 2(1), pp. 36-51, 1989. http://dx.doi.org/10.1108/09513578910132240

[26] Cooke, T.E., Voluntary corporate disclosure by Swedish companies. Journal of International Financial Management and Accounting, 1(2), pp. 171-195, 1989. http://dx.doi.org/10.1111/j.1467-646X.1989.tb00009.x

[27] Gray, S., Towards a theory of cultural influence on the development of accounting systems internationally. Abacus, 24(1), pp. 1-15, 1988.

http://dx.doi.org/10.1111/j.1467-6281.1988.tb00200.x 